\section{SAT0507 CLINICAL CHARACTERISTICS AND TREATMENT RESPONSE IN JUVENILE GOUT PATIENTS: A SINGLE CENTER EXPERIENCE}

S. Zheng', P. Y. Lee ${ }^{2}$, Y. Huang', Q. Huang', S. Chen ${ }^{1}$, T. W. Li'. ' 'Guangdong Second Provincial General Hospital, Guangzhou, China; ${ }^{2}$ Boston Children's Hospital, Boston, United States of America

Background: The incidence of juvenile gout is increasing in China. The clinical manifestations of juvenile gout and treatment strategies to reduce uric acid levels in children are not well described due to the limited number of cases in the past. Objectives: We aim to describe the clinical characteristic of children with gout and study the treatment response to febuxostat.

Methods: These studies were approved by the Institutional Review Board of Guangdong Second provincial General Hospital. We performed a retrospective analysis on 98 juvenile gout patients (age $\leq 18$ years) evaluated in our hospital from Jan 2016 to Dec 2019. We analyzed clinical parameters, laboratory data and treatment response. Results: The average age of disease onset in children with gout was $15.2 \pm 2.0$ years and the youngest patient was 9 years old. The majority of patients were male (94/98) and mean serum uric acid (sUA) level were 705.8 $\pm 145.7 \mu \mathrm{mol} / \mathrm{L}$ (reference range $<420 \mu \mathrm{mol} / \mathrm{L}$ ). More than half of the cohort had normal body mass index (mean $24.7 \pm 4.7 \mathrm{~kg} / \mathrm{m}^{2}$; range 14.9 to $36.1 \mathrm{~kg} / \mathrm{m}^{2}$ ). Renal function was generally normal in these children (serum creatinine $96.9 \pm 17.8 \mu \mathrm{mol} / \mathrm{L}$ ). In terms of joint manifestations, juvenile gout preferentially affected finger joints $(29 \%)$, ankles $(28 \%)$ and metatarsal joints (MTP; $20 \%$ ). The most frequent sites of initial gout attack were ankles (45\%), MTP $(39 \%)$ and fingers $(6 \%)$. In addition, tophi can occur in pediatric patients and typically develop in the finger joints (54\%). Tophi was observed in about $25 \%$ of juvenile gout patients, typically within the first two years of disease onset (mean duration $1.7 \pm 0.9$ years). We have found tophi in children as young as 10 years of age.

For treatment for chronic hyperuricemia, 32 patients $(32.7 \%)$ were started on febuxostat and 5 patients $(5.1 \%)$ received allopurinol. A decrease in sUA was observed in both groups after the first month of treatment (febuxostat: baseline $690.4 \pm 99.7 \mu \mathrm{mol} / \mathrm{L}$ to $482.7 \pm 140.8 \mu \mathrm{mol} / \mathrm{L}$ vs. allopurinol: baseline 728.8 $\pm 112.8 \mu \mathrm{mol} / \mathrm{L}$ to $565.0 \pm 116.7 \mu \mathrm{mol} / \mathrm{L}, \mathrm{P}=0.477)$. Serum uric acid of 6 patients in the febuxostat group (none in the allopurinol group) dropped below $360 \mu \mathrm{mol} / \mathrm{L}$. There were no statistical differences in Cr, AST and ALT between the groups. During follow-up after 3 months, further decline in SUA level were observed in patients treated with febuxostat $(409.5 \pm 83.4$, compared with baseline $\mathrm{P}<0.001)$. Conclusion: Juvenile gout has a different pattern of joint involvement and is less associated with elevated BMI compared to gout in adults. We show that febuxostat is effective in reducing uric acid levels in juvenile gout. These findings will help clinicians better understand the clinical manifestations and treatment response in juvenile gout.
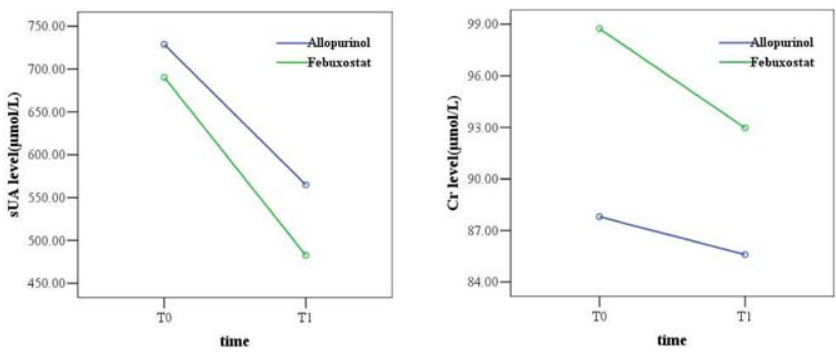

Figure 1 Compared treatment response with allopurinol and febuxosta

\section{References:}

[1] Kishimoto K, Kobayashi R, Hori D, et al. Febuxostat as a Prophylaxis for Tumor Lysis Syndrome in Children with Hematological Malignancies. Anticancer Res. 2017 Oct;37(10):5845-5849.

[2] Lu, C.C., et al. Clinical characteristics of and relationship between metabolic components and renal function among patients with early-onset juvenile tophaceous gout. J Rheumatol, 2014. 41(9): p. 1878-83.

Disclosure of Interests: None declared

DOI: 10.1136/annrheumdis-2020-eular.4622

\section{SATURDAY, 06 JUNE 2020}

\section{Other orphan diseases}

\begin{tabular}{l|l}
\hline SAT0508 & DIAGNOSIS OF BEHÇET'S DISEASE: COMPARISON \\
OF TWO SETS OF CLASSIFICATION CRITERIA. \\
APPLICATION IN 111 PATIENTS OF A WELL-DEFINED \\
POPULATION
\end{tabular}

C. Alvarez Reguera ${ }^{1}$, A. Herrero Morant ${ }^{1}$, L. Sanchez Bilbao ${ }^{1}$, D. MartínezLópez $^{1}$, J. L. Martín-Varillas ${ }^{1}$, G. Suárez Amorín ${ }^{2}$, P. Setien Preciados ${ }^{1}$,
M. C. Mata Arnaiz ${ }^{3}$, M. Á. González-Gay ${ }^{1}$, R. Blanco ${ }^{1} .{ }^{1}$ H.U.M. Valdecilla, Rheumatology, Santander, Spain; ${ }^{2}$ H.U.M. Valdecilla, Ophthalmology, Santander, Spain; ${ }^{3}$ Hospital de Laredo, Rheumatology, Laredo, Spain

Background: Behçet's disease (BD) is a systemic, chronic, relapsing vasculitis with no pathognomonic diagnostic test. The most widely used classification criteria are those of the International Study Group (ISG) for BD (1). These criteria were repeatedly found to have low sensitivity. Therefore, the International Criteria for Behçet's Disease (ICBD) were published in 2014 (2).

Objectives: To compare the ISG with ICBD diagnostic criteria for BD.

Methods: The study included all consecutive 111 patients diagnosed with definitive or possible BD by expert rheumatologists. They were diagnosed at a well-defined population in Northern Spain between 1980 and 2019. The ISG and ICBD diagnostic criteria for $\mathrm{BD}$ were applied to and compared among all patients.

Results: We studied 111 patients (62 Women/49 Men), mean age $36.8 \pm 13.2$ years. BD was diagnosed in $65(58.5 \%)$ by ISGBD criteria and in $86(77.5 \%)$ by ICBD criteria. No significant differences were observed between both criteria $(p<0.001)$. The overall concordance was fair (Kappa 0.3; $p<0.001)$. Sensitivity was $58.6 \%$ for ICBD criteria and $80.2 \%$ for ISG. (TABLE-1)

Conclusion: ICBD criteria exhibit higher sensitivity than ISG criteria. Thus, the application of these new criteria can achieve a more correct and earlier diagnosis of BD.

References:

[1] Criteria for diagnosis of Behcet's disease, International Study Group for Behçet's Disease, The Lancet, Volume 335, Issue 8697, 1078 - 1080

[2] The International Criteria for Behçet's Disease (ICBD): a collaborative study of 27 countries on the sensitivity and specificity of the new criteria, J Eur Acad Dermatol Venereol. 2014; 28:338-47

TABLE 1

\begin{tabular}{|c|c|c|c|}
\hline & $\begin{array}{l}\text { Expert diagnosis } \\
(\mathrm{N}=111)\end{array}$ & ISG criteria $-(\mathrm{N}=65)$ & $\begin{array}{l}\text { ICBD criteria } \\
(\mathrm{N}=86)\end{array}$ \\
\hline Age, mean (SD) & $36.7(13.2)$ & $36(12.8)$ & $36.7(13)$ \\
\hline Gender, men/women, N (\%) & $49 / 62(44.1 / 55.8)$ & 29/36 (44.6/55.4) & $38 / 48(44.2 / 55.8)$ \\
\hline Oral aphthosis & $110(99)$ & $65(100)$ & $85(100)$ \\
\hline -Recurrent (3 times/year) & $91(87.2)$ & $61(93.8)$ & $74(86)$ \\
\hline Genital aphthosis & $59(53.1)$ & $42(64.6)$ & $56(65.1)$ \\
\hline Skin manifestations & $76(68.4)$ & 56 (86.15) & 71 (70.9) \\
\hline -Pseudofolliculitis/ & $51(67.1) / 27(35.5)$ & $38(58.5) / 21(32.3)$ & $42(68.8) /$ \\
\hline Erythema nodosum & & & $22(36.1)$ \\
\hline Ocular lesions & $39(35.1)$ & $32(49.2)$ & $39(45.3)$ \\
\hline -Anterior/ Posterior/ & 17 (43.6); & $16(50) / 8(25) /$ & 17 (45.6); 0; \\
\hline Panuveitis & $12(30.8) / 0$ & $7(21.9)$ & $12(30.8)$ \\
\hline -Retinal vasculitis & $4(10.3)$ & $1(3.1)$ & $4(10.6)$ \\
\hline Joint manifestations & $76(68.5)$ & $43(66.1)$ & $58(67.4)$ \\
\hline \multirow[t]{2}{*}{-Arthralgias / Arthritis } & $69(92.8) / 45(60)$ & $39(90.7) / 24(55.8)$ & $52(89.6) /$ \\
\hline & & & $33(56.9)$ \\
\hline $\begin{array}{l}\text { Neurological } \\
\text { manifestations }\end{array}$ & $20(18)$ & $11(16.9)$ & $16(18.6)$ \\
\hline -Peripheral / Central & $11(55) / 14(70)$ & $7(63.6) / 7(63.6)$ & $\begin{array}{l}12(75) / \\
10(62.5)\end{array}$ \\
\hline Vascular manifestations & $9(8.6)$ & $7(10.8)$ & $10(11.6)$ \\
\hline $\begin{array}{l}\text {-Arterial/ Vein thrombosis/ } \\
\text { Phlebitis }\end{array}$ & $0 / 5(55) / 1$ (11.1) & $0 / 4(57.1) / 1(14.3)$ & $\begin{array}{l}1(12.5) / \\
5(62.5) / 0\end{array}$ \\
\hline Gastrointestinal features & $4(4.5)$ & $4(6.1)$ & $4(4.6)$ \\
\hline $\begin{array}{l}\text { Pathergy test positive } \\
\text { (available data; \%) }\end{array}$ & $6(28 ; 21.4)$ & $4(19 ; 21)$ & $4(25,16)$ \\
\hline $\begin{array}{l}\text { HLA B51 positive (available } \\
\text { data; \%) }\end{array}$ & $38(86 ; 44.2)$ & $19(47 ; 40.4)$ & $28(63 ; 44.4)$ \\
\hline
\end{tabular}

Disclosure of Interests: Carmen Alvarez Reguera: None declared, Alba Herrero Morant: None declared, Lara Sanchez Bilbao: None declared, David Martínez-López: None declared, José Luis Martín-Varillas Grant/research support from: AbbVie, Pfizer, Janssen and Celgene, Speakers bureau: Pfizer and Lilly, Guillermo Suárez Amorín: None declared, Patricia Setien Preciados: None declared, M. Cristina Mata Arnaiz: None declared, Miguel Á. GonzálezGay Grant/research support from: AbbVie, MSD and Roche, Speakers bureau: AbbVie, MSD and Roche, Ricardo Blanco Grant/research support from: Abbvie, MSD and Roche, Consultant of: Abbvie, Pfizer, Roche, Bristol-Myers, Janssen and MSD, Speakers bureau: Abbvie, Pfizer, Roche, Bristol-Myers, Janssen, Lilly and MSD

DOI: 10.1136/annrheumdis-2020-eular.5166

\begin{tabular}{|l|l}
\hline SAT0509 & MYCOPHENOLATE MOFETIL VERSUS \\
& AZATHIOPURINE FOR THE MAINTENANCE \\
& TREATMENT OF CONNECTIVE-TISSUE RELATED \\
& INTERSTITIAL LUNG DISEASE FOLLOWING \\
& CYCLOPHOSPHAMIDE TREATMENT
\end{tabular}

H. Satış ${ }^{1}$, M. Onut ${ }^{1}$, R. Bilici Salman ${ }^{1}$, H. Babaoglu ${ }^{1}$, N. Atas ${ }^{1}$, A. Avanoğlu Güler $^{1}$, H. Karadeniz ${ }^{1}$, D. Yapar ${ }^{1}$, N. Kayahan ${ }^{2}$, S. Haznedaroglu', B. Goker ${ }^{1}$, 
M. A. Ozturk ${ }^{1}$, A. Tufan ${ }^{1}$, H. Türktaş ${ }^{1}{ }^{1}$ Gazi Univercity Faculty of Medicine Hospital, Ankara, Turkey; ${ }^{2}$ Gülhane Research and Training Hospital, Ankara, Turkey

Background: Cyclophosphamide (CYC) had a good response rates when used as an induction regimen for the treatment of connective tissue related interstitial lung disease (CTD-ILD). But the safety profile of CYC necessitates the usage of a second line treatment for maintenance

Objectives: To compare the effect of mycophonetil (MMF) and azatiyopurin (AZA) for maintanance therapy following cyclophsphomide treatment in CTD-ILD Methods: Between 2009 and 2019 all interstitial lung disease patients admitting rheumatology or pulmonology department were retrospectively evaluated and patients treated with cyclophospamide as an induction regimen and having not progression were selected. Among those, as a second line regimen treated with MMF or AZA were included. Primary end point was treatment responses at 6 th months

Results: 68 patients treated with CYC for the first line treatment. 46 patients treated with either MMF (n:22) or AZA (n:24) for the maintenance. Scleroderma patients were the largest group and consituted $63 \%$ of the population. MMF group had worse FVC values and more involvement in lung paranchyme at the begining of the treatment. In univariate analysis FVC (It) values and lung involvement (\%) on HRCT at the start of the treatment, and disease subtype were associated significantly with treatment responses.After adjusted with these factors, in multivariate analysis, AZA treatment was associated with the increased risk of progression (odds ratio $5,8,95 \% \mathrm{Cl} 1,061-31,09$ ) as compared with MMF treatment Conclusion: MMF had better results compared to AZA in the treatment of CTD-ILD, after the usage of CYC treatment.

References:

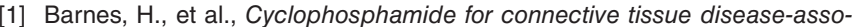
ciated interstitial lung disease. Cochrane Database Syst Rev, 2018. 1(1): p. Cd010908.

Table 1. Patient and disease characteristics at the start of the treatment and treatment responses at the 6th months of the treatment: FVC forced vital capacity

\begin{tabular}{lccr}
\hline & MMF (22) & AZA (24) & p \\
\hline Lung involvement (\%) & $36 \%$ & $23,3 \%$ & $\mathbf{0 , 0 2 2}$ \\
FVC (It) & 1,96 & 2,55 & $\mathbf{0 , 0 2 1}$ \\
FVC (\%) & $71 \%$ & $81 \%$ & $<\mathbf{0 , 0 0 1}$ \\
FVC change at 6th month (It) &,- 02 & $-0,19$ & $\mathbf{0 , 0 5 1}$ \\
FVC change at 6th month (\%) & $-0,42$ & $-5,81$ & 0,068 \\
Progression & $23,8 \%$ & $50 \%$ & $\mathbf{0 , 1 1 8}$ \\
\hline
\end{tabular}

Disclosure of Interests: None declared

DOI: 10.1136/annrheumdis-2020-eular.3879

\section{SAT0510 LONG-TERM EFFECTIVENESS OF CANAKINUMAB IN AID - INTERIM ANALYSIS OF THE CAPS SUBGROUP FROM THE RELIANCE REGISTRY}

N. Blank ${ }^{1}$, M. Borte ${ }^{2}$, I. Foeldvari ${ }^{3}$, G. Horneff ${ }^{4}$, T. Kallinich $^{5}$, B. Kortus-Goetze ${ }^{6}$, P. Oommen ${ }^{7}$, C. Schuetz ${ }^{8}$, F. Weller-Heinemann ${ }^{9}$, J. Weber-Arden ${ }^{10}$, J.

B. Kuemmerle-Deschner ${ }^{11}$. ${ }^{1}$ University Hospital, Heidelberg, Germany; ${ }^{2}$ Hospital St. Georg, Leipzig, Germany; ${ }^{3}$ Pediatric and Adolescence Rheumatology, Hamburg, Germany; ${ }^{4}$ Asklepios Clinic, Sankt Augustin, Germany; ${ }^{5}$ Charité University Medicine, Berlin, Germany; ${ }^{6}$ University Hospital, Marburg, Germany; ${ }^{7}$ Heinrich-Heine-University, Duesseldorf, Germany; ${ }^{8}$ University Hospital, UIm, Germany; ${ }^{9}$ Prof. Hess Kinderklinik, Bremen, Germany; ${ }^{10}$ Novartis Pharma GmbH, Nürnberg, Germany; ${ }^{11}$ University Hospital, Tübingen, Germany

Background: In the treatment of monogenic autoinflammatory diseases (AID), a heterogeneous group of diseases with excessive interleukin (IL)- $1 \beta$ release and severe systemic and organ inflammation, the anti-IL-1 inhibitor canakinumab (CAN) has been associated with rapid remission of symptoms in clinical trials as well as in real-life. ${ }^{1-3}$

Objectives: The aim of the RELIANCE registry is to explore long-term effectiveness and safety of CAN under routine clinical practice conditions in pediatric and adult patients with CAPS (cryopyrin-associated periodic syndromes, including Muckle-Wells syndrome [MWS], familial cold autoinflammatory syndrome [FCAS], neonatal onset multisystem inflammatory disease [NOMID]/ chronic infantile neurological cutaneous and articular syndrome [CINCA]), FMF (familial Mediterranean fever), TRAPS (tumor necrosis factor receptor-associated periodic syndrome) and HIDS/MKD (hyperimmunoglobulinemia D syndrome/ mevalonate kinase deficiency).

Methods: This prospective, non-interventional, observational study is based in Germany with a 3 -year follow-up and enrolls pediatric $\geq 2$ years and adult patients with clinically confirmed diagnoses of CAPS, FMF, TRAPS and HIDS/
MKD routinely receiving CAN. In 6-monthly visits, clinical data and patientreported outcomes are assessed. Study endpoints are long-term effectiveness and safety of CAN. Here, the CAPS cohort was analyzed.

Results: This 18-month interim-analysis includes 78 CAPS patients $49 \%$ females) enrolled by September 2019. Mean age at baseline was 25 years and mean duration of prior CAN treatment was 5.7 years. 64 patients $(82 \%)$ had MWS, 2 FCAS, 7 NOMID/CINCA, 3 atypical CAPS and 2 lacked subtype diagnosis. Disease activity, fatigue and social impairment by patients' assessment, days absent from school/work, inflammatory markers, and remission by physician assessment were evaluated at 6-monthly intervals starting at baseline with last update at 18 months of follow-up (table 1). The results demonstrate sustained remission and disease control as evaluated parameters remained stable over time. Serious adverse events were reported for 9 patients including papillitis pyrexia, tonsillitis $(n=2)$, appendicitis, chest pain, circulatory collapse, skin disorders, and preterm delivery.

Table 1. Patient and physician assessment of clinical CAPS disease activity and laboratory markers over time

\begin{tabular}{lcccc}
\hline & Baseline & 6 months & 12 months & 18 months \\
\hline Number of patients, N & 78 & 51 & 42 & 29 \\
Mean age, years (SD) & $25(4 ; 79)$ & $22(4 ; 79)$ & $20(4 ; 58)$ & $22(4 ; 54)$ \\
$\begin{array}{l}\text { Patient's assessment of disease activity } \\
\text { 0-10, }\end{array}$ & $2.2(0 ; 7)$ & $1.8(0 ; 7)$ & $2.4(0 ; 7)$ & $2.8(0 ; 8)$ \\
$\quad$ mean (min; max) & & & & \\
$\begin{array}{l}\text { Patient's assessment of fatigue 0-10 } \\
\text { Number (\%) of patients without impairment of }\end{array}$ & $2.9(0 ; 9)$ & $2.4(0 ; 8)$ & $2.8(0 ; 8)$ & $1.7(0 ; 7)$ \\
$\quad$ social life by disease & $29(76)$ & $20(61)$ & $14(67)$ \\
$\begin{array}{l}\text { Number (\%) of patients with days absent from } \\
\text { school/work }\end{array}$ & $25(32.5)$ & $11(22)$ & $14(34)$ & $15(52)$ \\
$\begin{array}{l}\text { Inflammatory markers, CRP/SAA, mean } \\
\text { (mg/dL) }\end{array}$ & 0.4 & 0.4 & 0.3 & 0.2 \\
$\begin{array}{l}\text { Number (\%) of patients in disease remission } \\
\text { (physician assessment) }\end{array}$ & $55(72)$ & $38(76)$ & $29(71)$ & $22(76)$ \\
\hline & & & & \\
\hline
\end{tabular}

Conclusion: The 18-month interim analysis of the RELIANCE study, the longest running real-life CAN registry, demonstrates that long-term CAN treatment is safe and effective in CAPS patients.

References:

[1] Lachmann et al. N Engl J Med. 2009;360(23):2416-25

[2] Kuemmerle-Deschner et al. Rheumatology (Oxford). 2016;55(4):689-96

[3] De Benedetti et al. N Engl. J Med. 2018;378(20):1908-1919

Disclosure of Interests: Norbert Blank Grant/research support from: Novartis, Sobi, Consultant of: Novartis, Sobi, Lilly, Pfizer, Abbvie, BMS, MSD, Actelion, UCB, Boehringer-Ingelheim, Roche, Michael Borte Grant/research support from: Pfizer, Shire, Ivan Foeldvari Consultant of: Novartis, Gerd Horneff Grant/research support from: AbbVie, Chugai, Merck Sharp \& Dohme, Novartis, Pfizer, Roche, Speakers bureau: AbbVie, Bayer, Chugai, Merck Sharp \& Dohme, Novartis Pfizer, Roche, Tilmann Kallinich Grant/research support from: Novartis, Consultant of: Sobi, Roche, Novartis, Birgit Kortus-Goetze Consultant of: Novartis, Prasad Oommen Consultant of: Novartis, Catharina Schuetz: None declared, Frank Weller-Heinemann: None declared, Julia Weber-Arden Employee of: I am employed by Novartis, J. B. Kuemmerle-Deschner Grant/research support from: Novartis, AbbVie, Sobi, Consultant of: Novartis, AbbVie, Sobi DOI: 10.1136/annrheumdis-2020-eular.6131

\section{SAT0511 CYTOKINES, CHEMOKINES AND INFLAMMATORY BIOMARKERS IN NEUROSARCOIDOSIS}

K. E. Byg ${ }^{1,2}$, Z. Illes ${ }^{2,3}$, T. Sejbaek ${ }^{4,5}$, A. Kindt ${ }^{6}$, T. Ellingsen ${ }^{2,7}$, H. Nielsen ${ }^{2,3}$. ${ }^{1}$ Odense University Hospital, University of Southern Denmark, Rheumatology, Odense C, Denmark; ${ }^{2}$ University of Southern Denmark, Clinical Research, Odense C, Denmark; ${ }^{3}$ Odense University Hospital, University of Southern Denmark., Neurology, Odense C, Denmark; ${ }^{4}$ South West Jutland Hospital, South Danish University Hospital, Neurology, Esbjerg, Denmark; ${ }^{5}$ University of Southern Denmark, Denmark, Regional Health Research, Odense C, Denmark; ${ }^{6}$ Odense University Hospital, University of Southern Denmark, Ophthalmology, Odense C, Denmark; ${ }^{7}$ Odense University Hospital, University of Southern Denmark., Rheumatology, Odense C, Denmark

Background: Sarcoidosis is characterized by granulomatous inflammation, which in rare cases can affect the central nervous system, neurosarcoidosis (NS).

Objectives: The aim of this study was to estimate levels of cytokines, chemokines, and vascular biomarkers in patients with NS.

Methods: In this observational, cross-sectional study, cerebrospinal fluid (CSF) and plasma were collected from biopsy-proven sarcoidosis patients with clinical suspicion of NS. They were categorized into either a NS group $(n=14)$ or a non-NS group $(n=5)$ depending on fulfilment of NS criteria. The results were 